University of Wollongong

Research Online

Faculty of Engineering - Papers (Archive)

Faculty of Engineering and Information

Sciences

$1-1-2007$

\title{
The simulation of magnetorheological elastomers adaptive tuned dynamic vibration absorber for automobile engine vibration control
}

\author{
X.C Zhang \\ University of Wollongong \\ X.Z. Zhang \\ University of Wollongong, xianzhou@uow.edu.au \\ W.H. Li \\ University of Wollongong, weihuali@uow.edu.au \\ B. Liu \\ University of Wollongong, bl384@uowmail.edu.au \\ X.L. Gong \\ University of Science and Technology of China
}

See next page for additional authors

Follow this and additional works at: https://ro.uow.edu.au/engpapers

Part of the Engineering Commons

https://ro.uow.edu.au/engpapers/2674

\section{Recommended Citation}

Zhang, X.C; Zhang, X.Z.; Li, W.H.; Liu, B.; Gong, X.L.; and Zhang, P.Q: The simulation of magnetorheological elastomers adaptive tuned dynamic vibration absorber for automobile engine vibration control 2007, 418-424.

https://ro.uow.edu.au/engpapers/2674

Research Online is the open access institutional repository for the University of Wollongong. For further information contact the UOW Library: research-pubs@uow.edu.au 
Authors

X.C Zhang, X.Z. Zhang, W.H. Li, B. Liu, X.L. Gong, and P.Q Zhang 


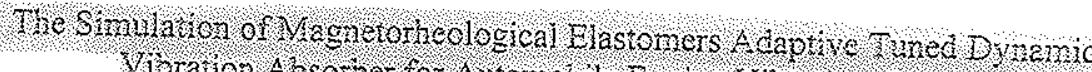

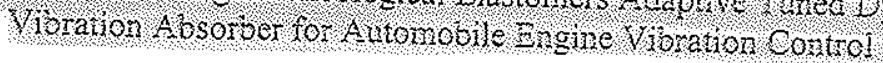

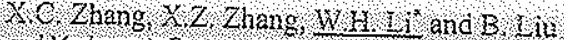

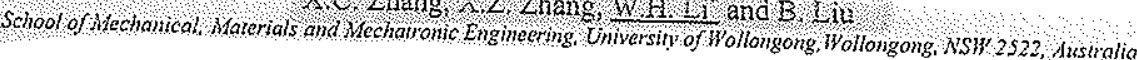

\section{L Gong and P Q Zhang}

CAS Key Labortary of Mechanical Behavior and Design of Materials, Deparmen of Mechanics and Mechanical

Engineering, University of Science and Techology of China, Kefei 230027, Chino

Abstract: The aim of this article is to investigate the use of a Dynamic Vibration Absorber to control vibration of engine active methods. This study is difierent in that it involves an adaptive colved the use of passive and more recently, using magnetorheologicai elastomers (MRES) as the adaptive dupuve component in the design of vibration absorber MRES are kind of novel smart (matrias as the adaptive spring.

paper, the vibration mode of a simple mod wose shear modulus can be controlled by applied magnetic field. In this analysis. Based on the analysis, the MREs Adaptive Tunede engine is simulaied by Finite Element Method (FEM) reduce the vibration of the engine Simes Adaptive Tuned Dynamic Vibration Absorber (ATDVA) is presented to by modifing the strear modulus of FENí analysis.

Keywords: magnelorheological elastomers, field-dependent shear modulus, Dynamic vibration absorber, Finite
Element Method

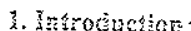

Most of mechanical, civil and construction systems are suffered from undesirable vibrations, which may damage the systems or even make the systems fail. In adoition, velicie manufacturers are continuously searching for ways in which vehicle refmement can be improved and its cost reduced. This noise. Consumers of a wide range of noise sources from engine structure-borne noise to airborne type car manufachurers are placing vehicle refinement com and refinement from all passenger cars. In response, therefore, of great importang vehicie refinemen at the heart of their product development strategies. It is, [1-2].

Among all vibration control devices, research on Tuned Dynamic Vibration Absorbers (TDVAs) is, Since their invention terms of total mumber of investigations and the time devoted to these investigations. structures. However, in 1900 s [1], TDVAs have effectively suppressed vibrations of machines and frequency ranges. In many practical applion conventional TDVA is always limited due to the narrow patterns and loading conditions. To plications, off-runing of a TDVA occurs because of varying usage Absorbers (ATDVAS) are extensively studied these shortcomings, Adaptive Tuned Dynamic Vibration adaplive elements that can be used to change the ATDVA is similat to conventional TDVA but with

\footnotetext{
"Corresponding author. Email; weihuali@urow.eduan
} 
Generally, ATDVA designs adont wo maior groups: one is to use variabie geometries and the ohe: is to ase smart or inelligent materials [3]. From the imporam view of system reliability and maintainability of ATDVA designs, Sun et al. [4] suggested the use of intelligent materials as alternatives. Davis et al. [5] suggested the use of a piezoelectric ceramic elements as part of the device stiffiness, and reported the use capacitive shunts to vary the device natural ifequency from $290 \mathrm{~Hz}$ to $350 \mathrm{~Hz}$. Flatau et al. [6] used the magnetostrictive material Terienol-D to develop an ATDVA that achieved a natural frequency variation from $1375 \mathrm{~Hz}$ to $2010 \mathrm{~Hz}$. Williams et al[3]] used the thermal actuation of shape memory alloys (SMA) as tuning materials to develop an ATDVA. Testing showed that the SMA ATVA natural frequency could be varied by approximately $15 \%$ from $38.5 \mathrm{H} z$ to $46.5 \mathrm{~Hz}$. Though many attempts have been made, there are still some shortcomings, such as low responses, complex structures, prune to working conditions, etc.

This paper proposes to design a new ATDVA working with a new intelligent material: MR elastomers. With the magnetic field increases, the shear modulus of $M R$ elastomers increases steadily. Renoval of the magnetic field, MR elastomers immediately reverse to their initial status. Based on these unique characteristics that their inechanical properties can be magnetically controlled, MR elastomers have found a lot of applications, such as dampers, engine mounts, and shock absorbers [8]. The use of MREs to develop ATDVAs are expected to have many advantages: very fast response (less than a few milli seconds), simple structure, easy implementation, good maintenance, high stability, and effective control. Ginder et al. [S] did a pioneer work that utilized MR elastomers as variable-spring-rate elements to develop an ATDVA. Their results indicated that a natural frequency zange from $580 \mathrm{~Hz}$ to $710 \mathrm{~Hz}$ at the magnetic field 0.56 Tesla. Gong et al. [9] used MR elastomers to develop an ATDVA and reported the natural frequency varying $50 \%$ from its centre frequency.

The crankshaft of autonobile engine is subject to dynamic torsional deformation as well as dynamic axial displacement, both causing vibration. Vibration control is of great importance because excessive vibration levels may damage the engine and create an annoying human environment. In this paper, the purpose of the new ADTVA is to suppress the vibration of an engine when the external stimulant forces with variant frequencies are added on this engine. Hence, before developing the new ATDVA, it is proposed to examine the validation of this ATDVA. FEM can be used over the complete frequency range of inierest. It provides a valuable tool for the rapid assessment of the noise implications of design changes, thereby reducing the number of options requixing detailed analysis. Following this, on the basis of the principle or the MREs and the vibration suppression, the finite element method is applied to build an engine model according to the properties of the engine 1.3L VVT2. The transmissibility of the engine model corresponding to stimulant forces with variant frequencies is calculated and recorded by the FEM too. Based on the simulation results, MATLAB is used to analyze and conclude the relationship between the properties of the MREs and the effect of the vibration suppression.

This paper is structured as four sections. In Section 1 , the inteligent material MR Elastomer is introduced, and its' changeable range of the shear modulus is discussed. In Section 2, the principle of the TDVA is explained. Section 3 is to demonstrate the Finite Element Modeling and the simulation resulis. Finally, the conclusion is given.

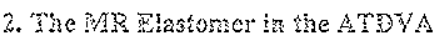

MR elastomers are suspensions of magnetized particles dispersed in a polymer medium, such as rubbers [7]. When individual particles are exposed to an applied magnetic field, magnetic dipole moments pointing along the magneaic field are induced in the particles. Pairs of particles then form headro-tail chains. After the matrix is cured, the particles are locked into place and the chains are firmly embedded in the matrix[11]. For particle concentrations of interests, the shear nodulus $G$ of the elastomer filled with dispersed rigid particles can be calculated with acceptable accuracy by following function [10],

$$
G=G_{0}\left(1+2.5 \phi+14.1 \phi^{2}\right)
$$

Here $G_{0}$ is the shear modulus of the unfilled elastomer, while $\phi$ is volume fraction of particles.

According to [8], the field induced modulas of MREs is in direct proportion to the magnetic intensity controlled by the electrical current intensity in the coil enlaced on the absorber. By assuming MRE is as same as the one in [8], corresponding to the elastomer with variant density of rigid parcels, the changeable range of the shear moduhs $\Delta G$ can be represented by

$$
\frac{\Delta G}{G(0)}(\max )=\frac{0.1911 \mathrm{MPa}}{G_{0}} \quad \text { when } \phi=0.266 \text {. }
$$

Iere typically, $G_{0}$ is close to $1.1 \mathrm{MPa}$. Therefore, $\Delta G / G(0)$ (max) could be roughly equal to $50 \%$. Following this, the changeable range of the shear modulus of the MiRE is located berween $1.1 \mathrm{MPa}$ and 1.5 $\mathrm{MPa}$.

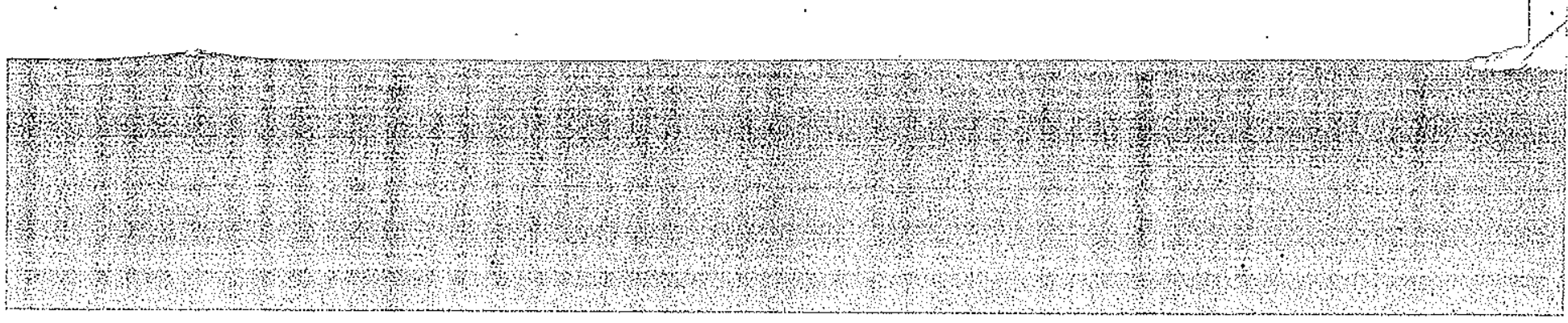




\section{ADYA}

Suppose a mass-spring system or a primary system is excited by a hamonic criving force farinot. When the driving frequency equals to the natural frequency of the system, the response is infinite. The TDV $A$ is essentially a secondary mass attached to the primary system via a spring and a damper. When the natural freguency of the TDVA is tumed such that it coincides with the frequency of unwanted vibration in the primary system, the vibration of the primary sysiem is greatly reduced. Thus, the energy of the primary system is apparently "absorbed" by the TDVA (Fig.1).

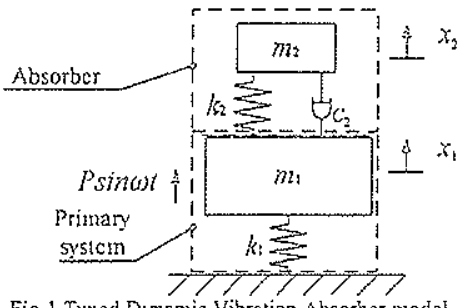

Fig.1 Tuned Dymanic Vibration Absorber model

The vibration reduction efficiency can be preparatory predicted by using a simplest model based on classical vibration tizeory. According to [12], a series of paramelers are defined and shown in table 1 .

\begin{tabular}{|c|c|c|c|}
\hline$\omega_{n 1}=\sqrt{\frac{k_{1}}{m_{1}}}$ & $\begin{array}{c}\text { Tabie. I Parameters for builing the mathematical model } \\
\text { frequency of } \\
\text { structure }\end{array}$ & $\omega_{n=2}=\sqrt{\frac{k_{2}}{m_{2}}}$ & $\begin{array}{c}\text { Natural } \\
\text { frequency of TDVA }\end{array}$ \\
\hline$\varsigma_{1}=\frac{c_{1}}{2 \omega_{n:} m_{2}}$ & $\begin{array}{c}\text { Damping ratio } \\
\text { of structure }\end{array}$ & $\varsigma_{z}=\frac{c_{2}}{2 \omega_{n}: m_{2}}$ & $\begin{array}{c}\text { Damping ratio } \\
\text { of TDVA }\end{array}$ \\
\hline$n=\frac{m_{3}}{m_{1}}$ & Mass ratio & $r=\frac{\omega}{\omega_{n 1}}$ & $\begin{array}{c}\text { Force } \\
\text { freguency ratio }\end{array}$ \\
\hline$g=\frac{\omega_{n-2}}{\omega_{n 1}}$ & $\begin{array}{c}\text { Natural } \\
\text { frequency ratio }\end{array}$ & $\delta_{s t}$ & $\begin{array}{c}\text { Static } \\
\text { defiection }\end{array}$ \\
\hline
\end{tabular}

Assume the stimulant force as $F=k_{1} \delta_{s t} e^{s t}$, the transmissibility equation for the force-exited system can be expressed as following:

$$
\frac{X_{1}}{\delta_{s t}}=\frac{\left(g^{2}-r^{2}+2 \zeta_{2} g r j\right)}{\left(-r^{2}+2 \varsigma_{1} r j+2 \varsigma_{2} \mu g r j+1+\mu g^{2}\right)\left(-r^{2}+2 \zeta_{2} r g j+g^{2}\right)-\mu\left(2 \varsigma_{2} g r j+g^{2}\right)^{2}}
$$

As expressed in this equation, withou changing the mass of the structure and the T.DVA, the only method to change the displacement of the system is to adjust the spring and damper of the TDVA.

In this example, by assuming the engine as the primary system, and the TDVA replaced by the ATDVA, the vibration suppression can be achieved successfully by adjusting $k_{3}$ and $c_{2}$. Becatse the values of the $k_{2}$ is related to the values of the shear modulus of the MREs, changing the shear modulus of the elastomer could be an officient method to adapt the requirements of the vibration suppression. As discussed in Section 2, since the shear modulus of the MREs can be adjusted from 1.MMPa to 1.5MPa by changing the flux, it is proposed that using MREs can directly develop a relationship between the fiux and the natural frequency of the system. In the following section, based on the parameters of the MR Elastomer, a FEM is applied to examine the validation of the new ATDVA.

\section{Finite Element Modeling ane Analyzing}

In order to examine the validation of the MRE semiactive vibration absorber, the engine 1.3L VVT2 is introduced in this paper. By respectively setting the passive tuned vibration adapter and the MRE semiactive vibration absorber on this engine in ANSYS simulation ervironment, the structural vibrations of the engine system are tracked and analyzed so as to demonstrate the effects of the proposed $M R Z$ vibration absoriber. 


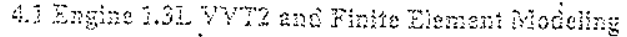

Based on the properties of engine $1.3 \mathrm{~L}$ VVT2, this simuiation model is simplified as a block with overall dimension of $607 \times 634 \times 605$ and mass of $138 \mathrm{~kg}$. Furthermore, berause treating the source of the vibration is the most effective and often the most economical solution to vibration problems, it is proposed to isolate the engine from the car base by the engine mounts with rubber part. Nomally, there are severa pairs of engine moints to fix the engine on the car base. Therefore, in the simulation model, the block represcnting the engine is attached by four rubber pads which are fixed in the simulation environment. Another function of the engine mounts is 10 isolate the car from the engine vibration in working status. The vibration transmissibility depends on distarbance frequency. Because a passive system is only cffective for disturbance with frequencies much higher than its natural frequency, the first compulsory work is to set the natural frequency of the system much less than the rotation speed of the engine which is from $63 \mathrm{~Hz}$ to $100 \mathrm{~Hz}$ so as to eliminate the influence from the engine. In this example, by predeining the properties of the four rubber pads, the natural frequency of the system is located around $43 \mathrm{~Hz}$.

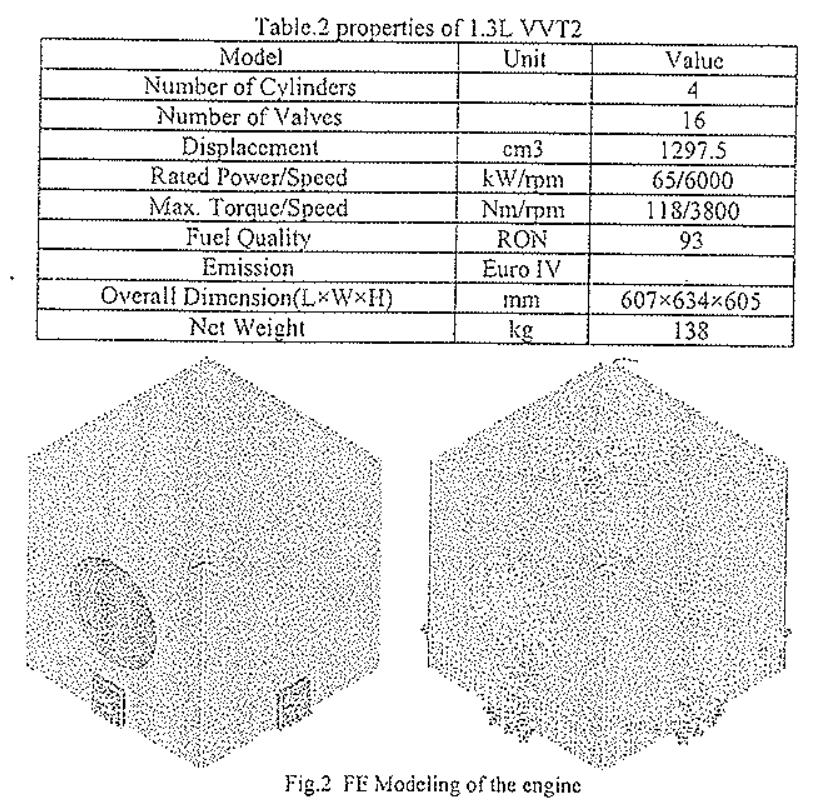

As the basis for numerical parametric studies for further evaluation of the dynamic performance of the proposed new ATDVA, the baseline model is built as shown in Fig.2. In order to reduce the calculations without influencing the accuracy of the simulation, the clement used to build this model is solid brick with 20 nodes; the meshing coefficient is set as ' 9 ' which is rough but acceptable.

On the purpose of observing the transmissibility of the engine model, a scries of stimulant forces are added on this engine. By considering the working stalus of the engine, the forces from the engine rotation provide the vibration in the vertical $(Z)$ and horizontal $(X$ and $Y)$ directions. In this simulation process, the frequency domain of the stimulant forces provided by the internal forces from the engine rotation are both set from $20 \mathrm{~Hz}$ to $100 \mathrm{~Hz}$, while the phase difference between the two directions ( $X$ and $Z$ ) of the forces from the engine rotation is set as $\pi / 2$ to simulate the rotary eccentic force.

By setting the frequency independent camping of the system as 0.05 , the transmissibility of the engine block in the three orthogonal directions can be illustrated in Fig.3. In this figure, it is obvious that the most prominent vibration is in the vertical $(Z)$ direction, while the others' amplitudes of the vibrations are much smaller. Fience, the focus of this FEM should be put on suppressing the vibration in the vertical direction. Because the amplitude of the vibration is directly related to the stimulant force, the transmissibility of !he system could be described as $\mathrm{s}$ miplitude/Force (m/N).

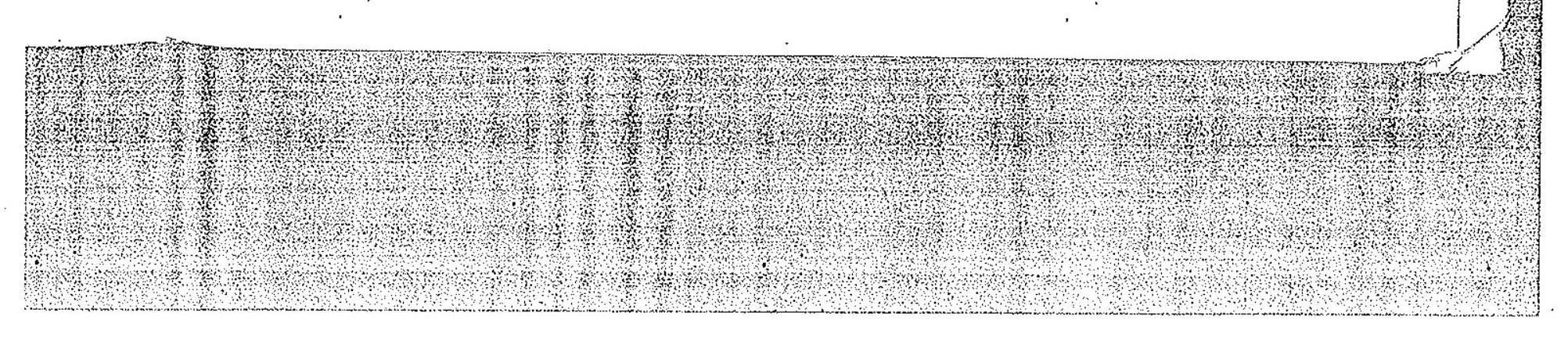




\subsection{Tned Vioration Absobs}

In order to suppress the vibration in a contimuch frequency comain, an $A T D V A$ model is adkd on the engine model as shown in Fig. The materials of the ATDVA are iefierred to the requirements of the design. Most part of the ATDVA is meshed roughly, while the MIR Elastomer is meshed in detail so as to guarantee the accuracy of the simulation.

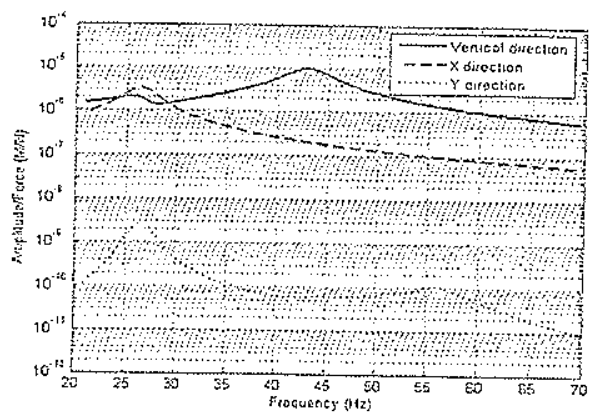

Fig. 3 Transmissibility response of the erigine
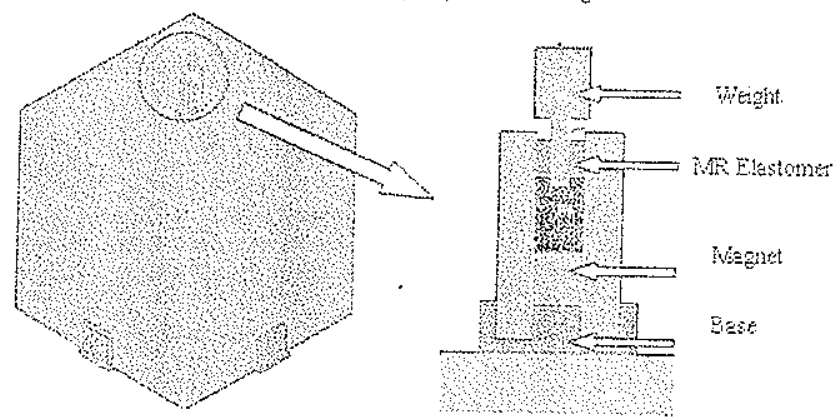

Fig. $4 \mathrm{FE}$. Nodeling of the engine equipped with ATDVA

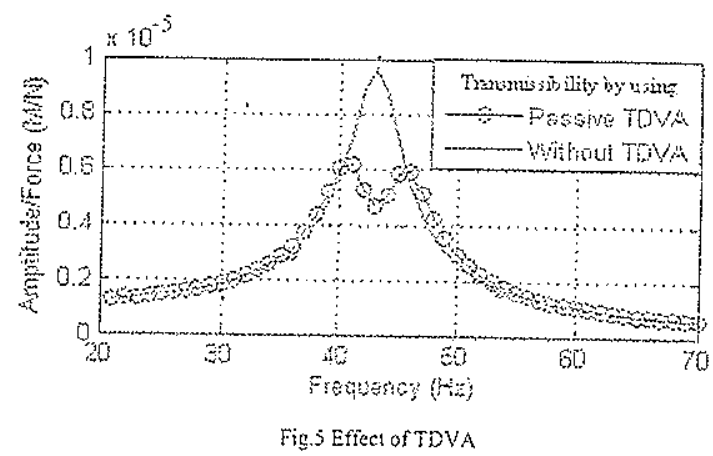

Based on the discussion in Section 2 and 3 , in this paper, the way to reduce the disturbance from the car base is to change the shear modulus of the MiR Elastomer so as to keep the natural frequency of the ATDVA as same as the frequency of the stimulant forces. In this example, the mass of the ATDVA is set as $1 \%$ of the engine, while the shear modulus is set around $1.3 \mathrm{MPa}$. The simuiation results are illustrated in Fig.5. 
As shown in this figure, there are ro peaks aroud the kesonance frequency, and this passive IVA is only capable of reducing the anplitudes between the two peaks. In order to exterd the capabijity of the TVA, it has been proposed that an Acaptive Tuied Dymanic Vibration Absorber (ATDVA) employing MREs must be designed and manuâctured. The basic magnetic field is generaed by a permanent magnet and the accessional magnetic intensity is controlled by the electrical current intensity in the coil. The induced magnetic field is imposed in the direction of particles' chains in WRES and it works at sibear modulus. Hence, this absorber is capable of instantaneously changing its stiffness, thus it can switch between resonance frequencies, increasing its effective bandwidth as compared to chassical TDVA for vibration control. Because a specific $M R$ Elastomer with changeable shear modulus from $1.1 \mathrm{MPa}$ to $1.5 \mathrm{MP}$ a is applied in this simulation, the validation of the new ATDVA must be examined based on this restriction. Therefore, this simulation could be considered as achieving a function to study the correlation between the shear modulus of the MREs and the viluration amplitude. Following this, by increasing the values of the shear modulus of the MREs, the amplinudes of the system stimulated by a series of multifrequency forces are derived as shown in Fig.6. By adjusting the values of the MREs" modutus according to disturbing force frequency, the effect of the new ATDVA is highlighted by comparing to the passive
TVA in Fig.7.

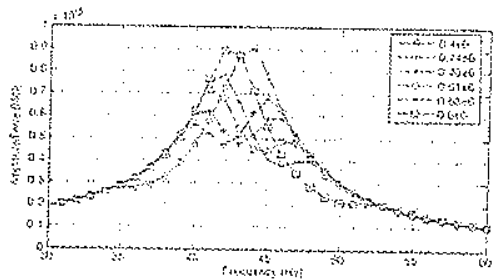

Fig.6 Vibration amplitudes corresponding to variant sicar modeltos of MRRES
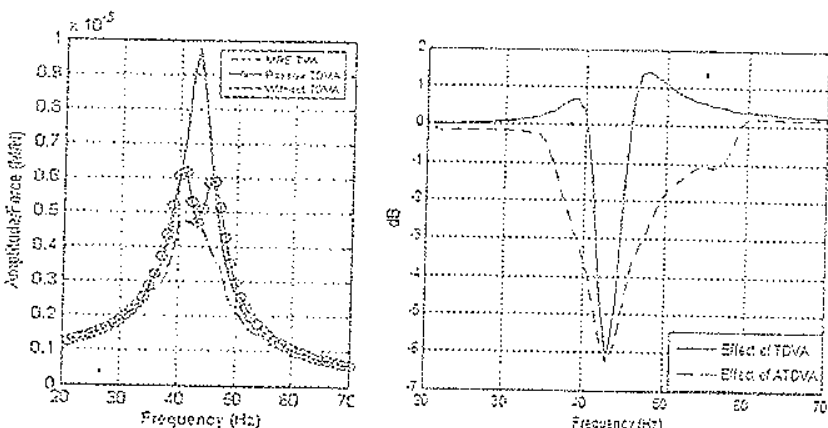

Fig. 7 The transmissibility of the system with passive and Semiactive TDVA

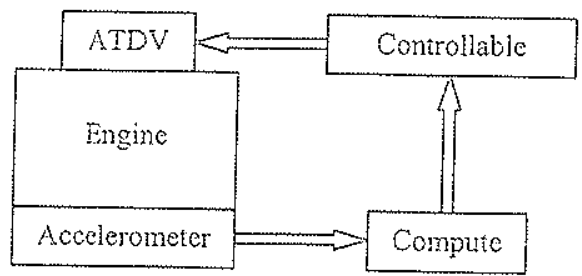

Fig.8 ATDVA Sy'stem

As demonstrated in above figure, it is obvious that the new ATDVA perforns much better than the passive TDVA whose sheas modulus cannot be adjusted. In the frequency domain of interest which is from $35 \mathrm{~Hz}$ to $50 \mathrm{~Hz}$, the vibration of the system camot only be suppressed in the natural frequency of the

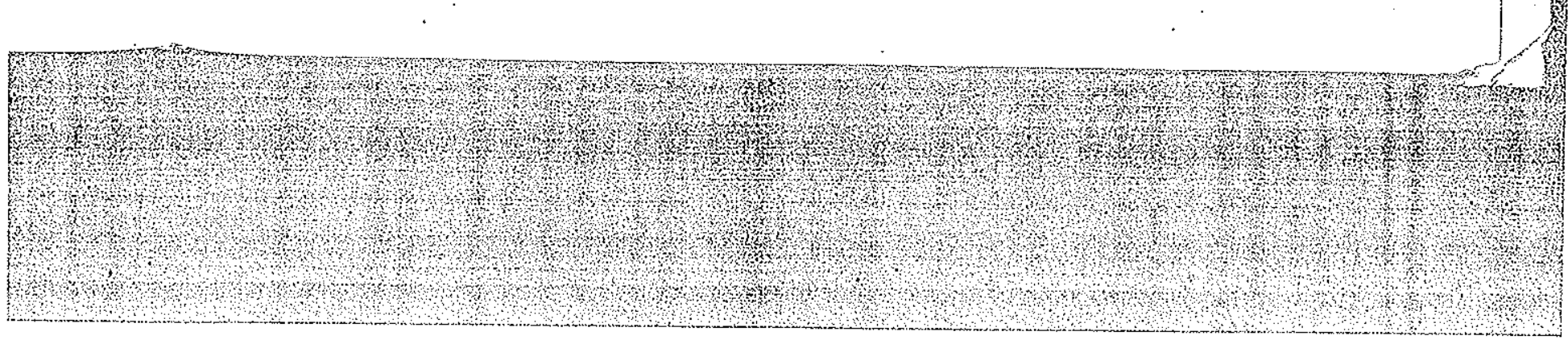




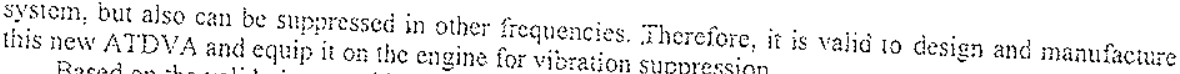
Based on the validation provice engme for vioration suppression.

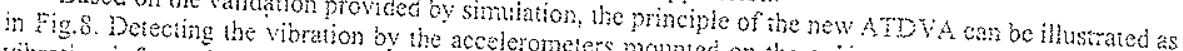
vibration infomation and provide control commands molinted on the engine, a system will analyse the intensity in coils which adjust the magnetic fied io the controllable power so as to change the current and 3 , the ATDVA will vary the naturatic field intensity around the MREs. As discussed in Section 2 new system will not only achieve natural freguency of the system in variant vibration situations, so that the new system will not only achieve the vibration isolation at different frequencies but also fulnil the overall
performance requirements.

\section{Conciusion}

In context of this paper, a new ATDVA employing MR Elastomer has been introduced to the engine validation of this new vibration absoriner principle of the MRE ATDVA, FEM is applied to evaluate the made as following.

Changing the

modulus of the MREs can shift in a reasonable by the electrical curent intensity in the coil, the shear it can be concluded that the elastic coefficient of the absorber the analysis resulis of the simulation, namal frequency of the ATDVA.

By tracking the frequency of

vibration in a wider frequency domain. The FEM also provioe of the whole system can be influenced greatly by shifting the a reliable evidence that the transmissibility range.

engine system, the FEM provides a reliable between the shear modulus and the iransmissibility of the higher the frequency of the stimulant force is, the in order to suppress the vibration of the engine, the Thereupon, the electrical current intensity in the coil should the shear modulus of MREs is required. the vibration of the system when the frequency of the stimulant force is increasing.

Peîersace

[1] Frahm H, Device for Damping Viorations of Bodics, (1909), U.S. Patent No: 989958.

2005;284:1181-1189.

[3] Williams KA Chin

absorber, J. Sound Vib., 2005:280.21) Dynamic modelling of a sizape memory alloy adaptive tuned vibration

[4] Sun JO Jolly MiR, Design, 1995;117B:234-242.

d. Vibration Absorbess-A Survey, J, Mech.

Piezoelectric Stifiness, J. Sound Vib Tumed Solid State Vibration Absorber Using Capacitive Shunting of

[6] Flatan AB, Dapinoss, J. Sound Vib., 2000;232:601-617.

SPIE, 1998;3327:463-473.

[7] Cartsc

[8] Ginder JM, Clark SM, Schlotter WF, Nicholastomer devices, Mechatronics, 2000; 10:555-569

elastomers, Int. J. Modem Phys. Q 2002:16, $170 ; 18: 2412$, Magnetostrictive phenomena in magnctorheological

[9] Gong XL, Zhang XZ, Zhang PQ, rabrication and Cha12-2418.

Polymer Testing, 2005;24:324.329.

[10] Davis LC, Modet of ,24:324-329.

[11] Bellan C, Bossis G, Field Dependogical elastomers, J. Appiied Phys., 1999;85(6):3348-3351,

Intemational Conference on ER Fluids and

[12] Koo JH, Using Magneto-Rheologids and MR Suspensions, 2002:507-513.

Vibrations, Blacksburg, Virginia, 2003:31-35. 
